\title{
Formation of motivational competence as a condition for successful professional development of future teachers-psychologists of inclusive education
}

\author{
L.Y. Belenkova ${ }^{1 *}$, and S.A. Sazonova ${ }^{2}$ \\ ${ }^{1}$ Moscow State University of Humanities and Economics, Moscow, Russia \\ ${ }^{2}$ Moscow State University of Humanities and Economics, Moscow, Russia
}

\begin{abstract}
The article reflects the problem of formation of students' motivational competence in an inclusive environment of the university (motivations of affiliation, achievement, self-actualization and value orientations of the individual), presents the results of experimental work, testing of training for the of professional motivation of students in the process of studying disciplines of socio-psychological orientation, contributing to their successful professional development.
\end{abstract}

\section{A problem statement}

The modern school needs such specialists who not only possess a certain amount of professional knowledge and skills, but are also motivated to work in an inclusive educational environment, striving for self-education, achieving the life success of each student, which is a key indicator of the professional success of a teacher.

The process of preparing bachelors on Psychology and Pedagogy fields is multidimensional and time-consuming, because at the theoretical and practical level, the a student needs to master the methods of communication, management, interaction, diagnosis, forecasting, methods and means of correction, rehabilitation and protection of the individuals. These fundamental components of students future professional activities should determine the content side of training the professionals who are ready to carry out teaching activities in an inclusive education.

The structure of professional competence of a teacher-psychologist, along with professional basic knowledge and skills, should include value orientations that characterize his motives and preferences. These are the motives that encourage pedagogical activity determines the effectiveness and efficiency of that particular activity, says M.G. Yanova $[1]$.

The motivational component of the teacher's professional competence, according to E.M. Borodulina, A.G. Portnova, E.S. Kagan, performs an energetic function, which implies the teacher's desire to assimilate new knowledge and acquire the personal meaning of this knowledge, to learn and develop a personal and professional growth (mobility); to

\footnotetext{
*Corresponding author: prof-ped.gpa@mail.ru
} 
develop readiness to implement the acquired knowledge and skills in teaching activities; to create the need to achieve extraordinary results, etc [2].

Motivational competence consists of the ability of a teacher's self-motivation to perform certain professional actions based on values, needs, and motives that correspond to the goals and objectives of inclusive learning. This competence is one of the priorities, since it determines the effectiveness of the educational process both at the university and in the future work of a teacher-psychologist in an inclusive educational institution.

The motives and competencies are unique to professionals who are capable of long-term performance without close supervision. Motivational competence predicts behavioral actions and performance results. A teacher-psychologist with a high level of motivation for self-realization, as a rule, has a rich creative potential, manifested in the desire to achieve results in performance without personal pragmatic motivation. Such a teacher-psychologist gets satisfaction from the activity itself that has a deep personal meaning for him. Its distinctive feature is a high level of reflection, which is important for successful work in an inclusive educational field. A positive perception of oneself in the profession is the belief of a teacher-psychologist in one's own abilities. This includes expressing confidence in overcoming difficult circumstances, achieving goals, and working constructively through failures. In addition, the teacher's assessment and self-assessment, based on motivation for high-quality professional activity, can have a beneficial effect on the entire process of relationships between participants in the inclusive educational process [3].

Foreign researchers the inadmissibility of focusing on individual competencies when it comes to inclusive education, and point out to the need for a broader approach to the idea of competence formation [4].

The opinion of Sevtap Karaoglu, who is convinced that the certain thing of about motivation is passion, which is related to the inner goals and desires of an individual, can be found interesting. In general, the success of a person is determined by how well he knows his preferences, his strengths and weaknesses. It both effectively exploits strengths and compensates for weaknesses [5].

The motives and competencies are unique to professionals who are capable of a longterm performance without close supervision. Motivational competence predicts behavioral actions and performance results. Therefore, a number of studies have identified a higher rank position for motivational competence than for cognitive and operational competencies [6].

The researches made by M. Lyle, J.R. Spencer also presents a step-by-step implementation of motivational competence: a motivation to achieve goal setting, personal responsibility, use of feedback, continuous improvement, quality of activity. In addition, M. Lyle, JR. Spencer revealed the types of competencies: superficial competencies (knowledge and skills), which are relatively easy to develop and evaluate, and deep competencies (motives and properties), which are the basis of personality; and also are more difficult to evaluate and develop [7].

It is noteworthy, the interdisciplinary nature of the study of the motivation of teaching and its practical significance, since no most effective educational technologies will be successful if students do not have cognitive interests, the desire to learn, receive and acquire knowledge. The research base has convincingly proved the connection of teaching with the personality of a student, on the one hand, and on the other - the connection with the social context of the learning. Therefore, we decided to turn to the analysis of the problem of educational motivation from the point of view of various scientific schools and directions. 
Thus, according to the theory of control and significance of emotions written by R. Pekrun, the influence of emotions is complex: emotions not only affect the educational process, but are also a key element of the identity of students and the basis of their wellbeing. With this in view, teachers, according to the author of this theory, should pay due attention to the emotions of their students [8].

Within the framework of the theory of achievement goals, students adhere to a certain cognitive-affective Self-concept, which is activated in a particular situation, generates selforiented directions, and manifests itself in the corresponding thoughts, feelings and behavior, which is confirmed by the results of research by T. Garcia, P.R. Pintrich [9].

The Attribution theory focuses on the fact that emotions relevant to achievement motivation can be caused by attributions of success and failure through a student's relationships with others. Martin A.J. and Dowson M. state that the features of interpersonal relationships of students in recent years are increasingly associated with educational motivation [10].

In the theory of expectations and values, great importance is also attached to the influence of others people and relationships with them in the process of forming educational motivation and achievements [11].

Followers of the various branches of the theory of interest and its influence on educational motivation agree that a well-developed individual interest contributes to the formation of long-term internal motivation and that students with a well-developed individual interest will continue to work or solve problems, regardless of difficulties and obstacles [12].

Within the framework of the theory of self-determination, in order to become motivated and to work at an optimal level, a certain set of psychological needs must be met, such as the need for competence, the need for autonomy and the need for interaction with other people [13].

\subsection{The objective of the work}

In the theory of self-efficacy during the study to educational motivation, the author considers the influence of students' relationships with others on this motivation. It is proved that it is possible for students to acquire a sense of self-efficacy through modeling situations with the resolution of problems, as well as with the support of significant others people. Exactly the relationships with others and the self-confidence that is maintained in these relationships, is the powerful source of modeling and positive communication [14].

According to the theory of transformative experience, the teacher should rethink learning in a way that increases the value of knowledge, applying it to life through various learning strategies. The process of learning should be structured according to three learning principles: it should present the material as ideas to be imagined, not as concepts to be learned, see new objects as new ideas and model transformative experiences [15].

It should also be noted that in the last decade, due to changes in the life of Russian society, the interest of local psychologists and teachers in the study of social motives of behavior has increased, since the role of the human personality in the surrounding social environment has increased. There is a particular need to find opportunities for the development of positive motives of social behavior, such as the motives of affiliation, achievement of success, self-actualization and value orientations of the individual. In the works of scientists, such as V.K. Vilyunas [16], V.I. Kovalev [17], A.N. Leontiev [18] the 
provisions on the polymotivation of activity are discussed. The motives for choosing a future profession are important factors that determine the success of professional training during the period of study at the university. Professional motives that are formed at the university are a kind of guarantee of the student's satisfaction with the profession itself in the real conditions of professional activity, the desire for the quality of their work. This requires new approaches to the practical training of future teachers-psychologists, which involves the development of educational programs, courses of lectures and practical classes, teaching aids for the formation of professional motivational competence [19].

\section{Results of the research}

The implementation of the process of developing the professional motivation of students in the inclusive conditions of the university in the process of studying the disciplines of sociopsychological orientation was based on the following basic psychological and pedagogical conditions:

- the formation of the motivation of affiliation, motivation of achievements, motivation of self-actualization and value orientation of students in the process of studying psychology should be one of the tasks of the professional activity of a university teacher;

- the goals of the development of the above-mentioned types of motivation should include availability of students with positive motivational states characterized by a focus on active interaction in the process of communicative activity, as well as providing a positive Self-concept that focuses on success;

- the development of motivations by a teacher is important to carry out in unity with the self-development of motivations by students on account of including them in the process of evaluating their own mental states and the results of educational activities;

- the development of motivations involves the use of a complex of psychological and pedagogical tools that have the appropriate developmental capabilities and implement the patterns of the development of motivation.

The main purpose of psychological support of these disciplines was to provide psychological support to the personality of a bachelor-psychologist and a teacherpsychologist, aimed at strengthening motivation, developing awareness of the features of the chosen professional activity, their personal characteristics and possible ways of professional development.

The training program for the development of professional motivation involved solving the following tasks: understanding the main personal meanings of professional activity, correlating them with students' ideas about satisfaction with professional activity; understanding the hierarchy of their own social roles and determining the place of the professional role in the overall life perspective; understanding and designing personal professional goals and goals of self-actualization; understanding the specifics of the implementation of career choices; formulation and selection of a possible professionalization strategy, personal professional programs.

The purpose of the study: the development of students' motivation of affiliation, achievements, self-actualization and value orientation of the individual in the process of studying the disciplines of socio-psychological orientation by means of training for the development of professional motivation, as a condition for the success of the professional formation of a teacher-psychologist. 
The tasks of the experimental work were as follows: 1) to analyze the psychological and pedagogical literature on the problem of research; 2) to make a set of diagnostic tools for studying the motivations of affiliation, achievement motivation, self-actualization motive and value orientations of students ("Methodology for identifying attitudes aimed at altruism-egoism" by O.F. Potemkina; questionnaire of self-actualization by E. Shstrom in the adaptation of A.V. Lazukin; "Questionnaire for measuring affiliative tendencies and sensitivity to rejection" by A. Mehrabian; "Methods of diagnostics of the real structure of the value orientations of the individual" by S.S. Bubnov); 3) to design and to implement a training program for the development of professional motivation; 4) to test experimentally the effectiveness of the developed program.

The empirical study was conducted on the basis of the Moscow State University of Humanities and Economics during classes in the disciplines "Psychology", "Social Psychology", "Psychology of training", "Psychology of stressful and Post-stressful situations" at the Faculty of Psychology and Pedagogy. In total, 110 students of 1-4 courses took part in the experiment, starting from 2017 to 2021 . The results of the pilot study are shown in Tables 1-4.

The data of diagnostics of socio-psychological attitudes of the individual in the motivational-need sphere according to the method of O. F. Potemkina are reflected in Table 1.

Table 1. Comparative analysis of intra-group differences in indicators of socio-psychological attitudes of the individual in the motivational-need sphere according to the method of O. F. Potemkina before and after the formative stage of the experiment using the Fisher's $\varphi$-criterion.

\begin{tabular}{|c|c|c|c|c|c|c|c|c|}
\hline \multirow{2}{*}{ Stages of the experiment } & \multicolumn{8}{|c|}{ Socio-psychological attitudes } \\
\cline { 2 - 9 } & Altruism & \multicolumn{2}{|c|}{ Egoism } & \multicolumn{2}{c|}{ Process } & \multicolumn{2}{c|}{ Result } \\
\cline { 2 - 9 } & abs. & $\mathbf{\%}$ & abs. & $\mathbf{\%}$ & abs. & $\mathbf{\%}$ & abs. & $\%$ \\
\hline Stating the case & 20 & 18.2 & 26 & 23.6 & 40 & 36.4 & 24 & 21.8 \\
\hline Control report & 35 & 31.8 & 13 & 11.8 & 25 & 22.7 & 37 & 33.7 \\
\hline $\begin{array}{c}\text { The magnitude and } \\
\text { significance of the } \varphi \text {-criterion }\end{array}$ & \multicolumn{2}{|c|}{$2.351^{*}$} & \multicolumn{2}{|c|}{$2.329^{*}$} & \multicolumn{2}{|c|}{2.24} & \multicolumn{2}{|c|}{1.965} \\
\hline
\end{tabular}

Note: $* 1.64-\mathrm{p} \geq 0.05, * * 2.31-\mathrm{p} \geq 0.01$

Table 4 shows, that at the ascertaining and control stages of the experiment, the egoistic tendency was revealed in $23.6 \%$ and $11.8 \%$ of respondents, respectively, they were characterized by concern for their own benefit, they put their interests above the interests of others; the altruistic tendency was characterized by $18.2 \%$ and $31.8 \%$ of respondents, respectively, they were characterized by recognition of the need for assistance, refusal to satisfy personal interests in favor of another person and the desire to act in accordance with the normative position; process orientation was typical for $36.4 \%$ and $22.7 \%$ of respondents, respectively, they were more process-oriented, less think about achieving results, are often late with the delivery of work, their procedural orientation hinders their effectiveness; they were more driven by interest in the case, and to achieve the result requires a lot of routine work, a negative attitude to which they could not overcome; result orientation was characteristic of $21.8 \%$ and $33.7 \%$ of respondents, respectively, they were result-oriented, reliable; they could achieve results in their activities in spite of obstacles and failures. The analysis of intra-group differences using the Fisher's $\varphi$-test for the indicators "altruism" and "egoism" revealed statistically significant differences at the p 0.01 
level of significance, and for the indicators "process" and "result" at the p 0.05 level of significance.

The data of diagnostics of self-actualization of the personality according to the method of E. Shstrom in the adaptation of A.V. Lazukin are reflected in Table 2.

Table 2. Comparative analysis of intra-group differences in the levels of self-actualization of the respondents ' personality according to the method of E. Shstrom in the adaptation of A.V. Lazukin before and after the formative stage of the experiment using the Fisher's $\varphi$-criterion.






\begin{tabular}{|c|c|c|c|c|c|c|c|c|}
\hline \multirow{2}{*}{\multicolumn{3}{|c|}{\begin{tabular}{c|c} 
& report \\
$\begin{array}{c}\text { The magnitude and significance of } \\
\text { the } \varphi \text {-criterion }\end{array}$
\end{tabular}}} & & & & & & \\
\hline & & & \multicolumn{2}{|c|}{$2.514^{* *}$} & \multicolumn{2}{|c|}{$3.834 * *$} & \multicolumn{2}{|c|}{$2.032 *$} \\
\hline \multirow[t]{2}{*}{8} & \multirow[t]{2}{*}{$\begin{array}{l}\text { Self } \\
\text { Understanding }\end{array}$} & $\begin{array}{l}\text { Stating the } \\
\text { case }\end{array}$ & 28 & 25.5 & 62 & 56.4 & 20 & 18.2 \\
\hline & & $\begin{array}{l}\text { Control } \\
\text { report }\end{array}$ & 45 & 40.9 & 55 & 50 & 10 & 9.1 \\
\hline \multicolumn{3}{|c|}{$\begin{array}{l}\text { The magnitude and significance of the } \\
\qquad \text {-criterion }\end{array}$} & \multicolumn{2}{|c|}{$2.44 * *$} & \multicolumn{2}{|c|}{0.949} & \multicolumn{2}{|c|}{$1.988^{*}$} \\
\hline \multirow[t]{2}{*}{9} & \multirow[t]{2}{*}{ Autosympathy } & $\begin{array}{l}\text { Stating the } \\
\text { case }\end{array}$ & 11 & 10 & 73 & 66.4 & 26 & 23.6 \\
\hline & & $\begin{array}{l}\text { Control } \\
\text { report }\end{array}$ & 27 & 24.5 & 67 & 60.9 & 16 & 14.6 \\
\hline \multicolumn{3}{|c|}{$\begin{array}{l}\text { The magnitude and significance of the } \\
\qquad \text {-criterion }\end{array}$} & \multicolumn{2}{|c|}{$2.907^{* *}$} & \multicolumn{2}{|c|}{0.845} & \multicolumn{2}{|c|}{$1.735^{*}$} \\
\hline \multirow[t]{2}{*}{10} & \multirow[t]{2}{*}{$\begin{array}{l}\text { Contact } \\
\text { information }\end{array}$} & $\begin{array}{l}\text { Stating the } \\
\text { case }\end{array}$ & 33 & 30 & 56 & 50.9 & 21 & 19.1 \\
\hline & & $\begin{array}{l}\text { Control } \\
\text { report }\end{array}$ & 46 & 41.8 & 53 & 48.2 & 11 & 10 \\
\hline \multicolumn{3}{|c|}{$\begin{array}{c}\text { The magnitude and significance of the } \\
\varphi \text {-criterion }\end{array}$} & \multicolumn{2}{|c|}{$1.832 *$} & \multicolumn{2}{|c|}{$3.189^{* *}$} & \multicolumn{2}{|c|}{$1.936^{*}$} \\
\hline \multirow[t]{2}{*}{11} & \multirow{2}{*}{$\begin{array}{l}\text { Flexibility in } \\
\text { communicatio } \\
\mathrm{n}\end{array}$} & $\begin{array}{l}\text { Stating the } \\
\text { case }\end{array}$ & 34 & 30.9 & 62 & 56.4 & 14 & 12.7 \\
\hline & & $\begin{array}{l}\text { Control } \\
\text { report }\end{array}$ & 52 & 47.3 & 48 & 43.6 & 10 & 9.1 \\
\hline \multicolumn{3}{|c|}{$\begin{array}{c}\text { The magnitude and significance of the } \\
\varphi \text {-criterion }\end{array}$} & \multicolumn{2}{|c|}{$2.507 * *$} & \multicolumn{2}{|c|}{$1.906^{*}$} & \multicolumn{2}{|c|}{0.86} \\
\hline
\end{tabular}

Note: $* 1.64-p \geq 0,05, * * 2.31-p \geq 0,01$

The data in Table 2 show that at the ascertaining and control stages of the experiment, $13.6 \%$ and $31.8 \%$ of respondents, respectively, had high indicators on the time orientation scale, i.e., these were respondents who were able to enjoy the current moment, which was not compared with past joys and was not devalued by the expectation of future success; these were respondents who were well aware of the existential value of life "here and now"; $22.7 \%$ and $11.8 \%$ of respondents, respectively, had a low result, which is was characteristic of people who were neurotically immersed in the experiences of the past, with an overestimated desire for achievements, suspicious and insecure.

Considering the indicators on the scale of values, it can be noted that $17.3 \%$ and $31.8 \%$ of respondents, respectively, had a high indicator, therefore, the choice of the values listed by them (truth, goodness, beauty, integrity, lack of duality, vitality, uniqueness, perfection, accomplishment, justice, order, simplicity, ease without effort, self-sufficiency), determines the desire for healthy relationships with people and harmonious being, the lack of desire to manipulate people in their interests. $20.9 \%$ and $6 \%$ of respondents had low indicators on the value scale, respectively.

A positive view of human nature is was formed in $4.5 \%$ and $21.8 \%$ of students, respectively; these respondents were differed by belief in mankind and in the power of their abilities, which is was interpreted as a stable basis for sincere and harmonious interpersonal relationships, sympathy and trust in man, honesty, benevolence; $30 \%$ and $17 \%$ of respondents, respectively, had a low level on the scale of ideas about human nature, i.e. they 
tended to perceive human nature rather as negative; they were not characterized by sincere and harmonious interpersonal relationships, friendly, trusting relationships with people.

A high level of need for knowledge was revealed in $11.8 \%$ and $26.3 \%$ of students, respectively; these respondents were always open to new impressions, they were distinguished by a disinterested thirst for new things, an interest in objects that is was not directly related to the satisfaction of any needs; $28.2 \%$ and $17.3 \%$ of the subjects, respectively, had a low degree of expression of the desire to acquire knowledge about the world around them, which indicates a lack of educational activity of these respondents.

Considering the indicators of the scale of creativity or desire for creativity, it can be noted that $14.5 \%$ and $28.2 \%$ of the subjects, respectively, were characterized by a creative attitude to life, for $32.8 \%$ and $19.2 \%$ of respondents, respectively, a low desire for creativity was revealed.

Considering the indicators of autonomy, which is the main measure of a person's mental health, its completeness and integrity, it should be noted that $26.3 \%$ and $41.9 \%$ of young men and women, respectively, had high indicators, which characterized them with features such as vitality, self-support, maturity, independence and freedom; $10 \%$ and $23.6 \%$ of respondents had a low level of autonomy.

A high level of spontaneity was found in $28.2 \%$ and $14.5 \%$ of the subjects, respectively, they were able to spontaneously and directly express their feelings and emotions, they were characterized by natural behavior, they were confident and trust others; $30.9 \%$ and $19.1 \%$ of the subjects, respectively, were characterized by a low level of spontaneity, which means self-doubt and distrust of the world around them.

A high level on the self-understanding scale in $25.5 \%$ and $40.9 \%$ of respondents, respectively, shows the presence of sensitivity, sensitivity of the subjects to their desires and needs, they are not inclined to adjust their own tastes and assessments to external social standards; a low level, identified in $18.2 \%$ and $9.1 \%$ of respondents, respectively, was inherent in people who are insecure, focused on the opinions of others.

A high level of autosympathy, which is the natural basis of mental health and personal integrity, is characteristic of $10 \%$ and $24.5 \%$ of the study participants, respectively, they were characterized by a meaningful positive Self-concept, which was the basis of a stable adequate self-esteem; $23.6 \%$ and $14.6 \%$ of respondents, respectively, had low indicators of autosympathy, which characterizes them as neurotic, anxious, insecure people.

According to the contact scale, $30 \%$ and $41.8 \%$ of the subjects, respectively, were characterized by a high level of sociability, the ability to establish strong and friendly relationships with others, a tendency to mutually useful and pleasant contacts with other people; a low level is noted in $19.1 \%$ and $10 \%$ of the subjects, respectively, which determines the inability to quickly establish deep and close emotionally-saturated contacts with people.

The scale of flexibility in communication is compared with the presence or absence of social patterns, the ability to adequately express themselves in communication. The high level of indicators in $30.9 \%$ and $47.3 \%$ of respondents, respectively, characterizes them as people who are inclined to authentic interaction with others, capable of self-disclosure, they are not characterized by a tendency to resort to falsehood or manipulation; The low level of the indicator was noted in $12.7 \%$ and $9.1 \%$ of respondents, respectively, it was typical for people who were unsure of their attractiveness, they doubted that they were interesting to the interlocutor and communication with them can bring pleasure.

Recognizing the importance of self-development, self-actualization, students-future psychologists and teachers-psychologists after conducting training sessions began to 
possess a number of personal characteristics that allow them to fully realize their capabilities: a sufficiently high level of trust, a kind and attentive attitude to people, selfconfidence, a tendency to subordinate their own tastes and interests to the needs of the majority.

Considering the results of the self-actualization test, it can be noted that most of the respondents were characterized by an average level of self-actualization.

Analysis of intra-group differences in the levels of self-actualization of the respondents ' personality according to the method of E. Shstrom using the Fisher's $\varphi$-criterion for the indicators "high level" on all scales of the method revealed statistically significant differences and for the indicator "low level" on the scales "value, creativity and autonomy" at the p 0.01 level of significance, for the indicator "low level" statistically significant differences on the scales "orientation in time", "view of human nature, the need for knowledge", "spontaneity", "self-understanding", "autosympathy", "contact" at the p 0.05 significance level.

These methods of A. Mehrabian are reflected in Table 3.

Table 3. Comparative analysis of intra-group differences in the levels of development of affilative tendencies and sensitivity to rejection in students according to the method of A. Mehrabian before and after the formative stage of the experiment using the Fisher $\varphi$-test.

\begin{tabular}{|c|c|c|c|c|c|c|c|}
\hline \multirow[t]{3}{*}{ Motive } & \multirow{3}{*}{$\begin{array}{l}\text { Stages of the } \\
\text { experiment }\end{array}$} & \multicolumn{6}{|c|}{ The level of development of the motive } \\
\hline & & \multicolumn{2}{|c|}{ High } & \multicolumn{2}{|c|}{ Medium } & \multicolumn{2}{|c|}{ Low } \\
\hline & & abs. & $\%$ & abs. & $\%$ & abs. & $\%$ \\
\hline \multirow{2}{*}{$\begin{array}{l}\text { Striving for } \\
\text { people }\end{array}$} & Stating the case & 55 & 50 & 40 & 36.4 & 15 & 13.6 \\
\hline & Control report & 21 & 19.1 & 40 & 36.4 & 49 & 44.5 \\
\hline \multicolumn{2}{|c|}{$\begin{array}{l}\text { The magnitude and significance of the } \\
\qquad \varphi \text {-criterio }\end{array}$} & \multicolumn{2}{|c|}{$4.939 * *$} & \multicolumn{2}{|c|}{0} & \multicolumn{2}{|c|}{$5.236 * *$} \\
\hline \multirow{2}{*}{$\begin{array}{l}\text { Fear of } \\
\text { rejection }\end{array}$} & Stating the case & 26 & 23.7 & 38 & 34.5 & 46 & 41.8 \\
\hline & Control report & 58 & 52.7 & 43 & 39.1 & 9 & 8.2 \\
\hline \multicolumn{2}{|c|}{$\begin{array}{l}\text { The magnitude and significance of the } \\
\qquad \varphi \text {-criterion }\end{array}$} & \multicolumn{2}{|c|}{$4.524 * *$} & \multicolumn{2}{|c|}{0.705} & \multicolumn{2}{|c|}{$6.118 * *$} \\
\hline
\end{tabular}

Note: $* 1.64-\mathrm{p} \geq 0.05,{ }^{* * 2.31-p} \geq 0.01$

According to Table 3, at the ascertaining stage of the study, a low level of the motive of striving for people was revealed in $50 \%$ of respondents, at the control stage - in $19.1 \%$ of respondents, the average level of this motive - in $36.4 \%$ of respondents at the ascertaining and control stages, respectively, a high level - in $13.6 \%$ and $44.5 \%$ of respondents, respectively; At the ascertaining stage of the study, a low level of fear of rejection was detected in $23.7 \%$ of respondents, at the control stage - in $52.7 \%$ of respondents, the average level - in $34.5 \%$ and $39.1 \%$ of respondents, respectively, and a high level - in $41.8 \%$ and $8.2 \%$ of respondents, respectively.

The data of the test questionnaire for measuring the motivation of affinity allow us to distinguish 4 groups of the intensity of the manifestation of the motives of the desire for acceptance and the fear of rejection. $41.8 \%$ of the subjects showed a combination of the following positions: a high level of development of the motive "fear of rejection" in combination with a low level of development of the motive "desire for people", which characterizes them as actively avoiding contact with people, looking for loneliness. $13.6 \%$ of the subjects showed a combination of the following positions: a high level of 
development of the motive "desire for people", combined with a high level of development of the motive "fear of being rejected, which is characterized by a strong internal conflict between the desire for people and their avoidance, which occurs every time he has to meet with strangers. $13.6 \%$ of the subjects showed a combination of the following positions: a high level of development of the motive "desire for people", combined with a low level of development of the motive "fear of rejection", which characterizes them as actively seeking contacts and communication with people, experiencing mostly only positive emotions. In $23.7 \%$ of the subjects, a combination of motivational tendencies was revealed: a low level of development of both motives, which characterizes them as living among people and communicating with them, not experiencing either positive or negative emotions from this, and feeling well both among people and without them.

The analysis of intra-group differences using the Fisher's $\varphi$-test for the "low level" and " high level "of the" desire for people "and" fear of rejection " scales revealed statistically significant differences at the $\mathrm{p} 0.01$ significance level.

The diagnostic data of the real structure of the value orientations of the individual according to the method of S.S. Bubnov are presented in Table 4 (Table 4).

The data in Table 4 show that the priority value orientations according to the hierarchy of respondents at the ascertaining and control stages of the experiment were "high level" of the following scales: "help and mercy to people" - in $36.4 \%$ and $50 \%$ of respondents, respectively, "health" - in $26.4 \%$ and $41.8 \%$ of students, respectively, "love" - in $27.3 \%$ and $40 \%$ of respondents, respectively, " search and enjoy the beautiful» - in $22.7 \%$ of $40.9 \%$ of respondents, respectively, "social activity for achieving positive changes in society" $16.4 \%$ and $38.1 \%$ of respondents, respectively," high material well-being" was identified in $9.1 \%$ and $33.7 \%$ of respondents, respectively, "learning new things in the world, nature, and man" $16.3 \%$ and $32.7 \%$ of respondents, respectively, "communication" $12.7 \%$ and $24.6 \%$ of respondents, respectively.

The most unreadable values were: "rest, pleasant pastime" in $38.2 \%$ and $33.7 \%$ of respondents, respectively, "recognition and respect of people" in $38.2 \%$ and $45.5 \%$ of the subjects, respectively.

The analysis of intra-group differences using the Fisher's $\varphi$-criterion for the indicator " high level "of the scales" high material well-being", "search and enjoyment of the beautiful", "learning new things in the world, nature, man", " social activity and health "revealed statistically significant differences at the p 0.01 level of significance, the scales" help and mercy to other people"," love " revealed statistically significant differences at the $p$ 0.05 level of significance.

The determination of the statistical significance of the differences in the indicators of the formation of the motivational sphere of students in all the diagnostic methods used with the Fisher criterion confirmed the effectiveness of the experimental work on the development of the motivational sphere of personality in students-future psychologists and teacherspsychologists in the process of studying the disciplines of socio-psychological orientation by means of training for the development of professional motivation as a condition for the success of the professional formation of a psychologist and a teacher-psychologist. 
Table 4. Comparative analysis of intra-group differences in the levels of formation of value orientations of the respondents ' personality according to the method of S.S. Bubnov before and after the formative stage of the experiment using the Fisher's $\varphi$-criterion.

\begin{tabular}{|c|c|c|c|c|c|c|c|c|}
\hline \multirow[t]{3}{*}{ № } & \multirow{3}{*}{ Values } & \multirow{3}{*}{$\begin{array}{c}\text { Stages of the } \\
\text { experiment }\end{array}$} & \multicolumn{6}{|c|}{ Levels of value formation } \\
\hline & & & \multicolumn{2}{|c|}{ High } & \multicolumn{2}{|c|}{ Medium } & \multicolumn{2}{|c|}{ Low } \\
\hline & & & abs. & $\%$ & abs. & $\%$ & abs. & $\%$ \\
\hline \multirow[b]{2}{*}{1} & \multirow[t]{2}{*}{ Rest, pleasant pastime } & Stating the case & 15 & 13,6 & 53 & 48.2 & 42 & 38.2 \\
\hline & & Control report & 4 & 3.6 & 69 & 62.7 & 37 & 33.7 \\
\hline \multicolumn{3}{|c|}{ The magnitude and significance of the $\varphi$-criterio } & \multicolumn{2}{|c|}{$2.766 * *$} & \multicolumn{2}{|c|}{$2.173 *$} & \multicolumn{2}{|c|}{0.712} \\
\hline \multirow[b]{2}{*}{2} & \multirow[t]{2}{*}{ High material well-being } & Stating the case & 45 & 40.9 & 55 & 51 & 10 & 9.1 \\
\hline & & Control report & 30 & 27.2 & 43 & 39.1 & 37 & 33.7 \\
\hline \multicolumn{3}{|c|}{ The magnitude and significance of the $\varphi$-criterio } & \multicolumn{2}{|c|}{$2.136 *$} & \multicolumn{2}{|c|}{$1.632 *$} & \multicolumn{2}{|c|}{$4.628 * *$} \\
\hline \multirow[b]{2}{*}{3} & \multirow{2}{*}{$\begin{array}{l}\text { Search and enjoy the } \\
\text { beautiful }\end{array}$} & Stating the case & 55 & 50 & 30 & 27.3 & 25 & 22.7 \\
\hline & & Control report & 30 & 27.3 & 35 & 31.8 & 45 & 40.9 \\
\hline \multicolumn{3}{|c|}{ The magnitude and significance of the $\varphi$-criterio } & \multicolumn{2}{|c|}{$3.493 * *$} & \multicolumn{2}{|c|}{0.727} & \multicolumn{2}{|c|}{$2.929 * *$} \\
\hline \multirow[b]{2}{*}{4} & \multirow{2}{*}{$\begin{array}{l}\text { Help and mercy to other } \\
\text { people }\end{array}$} & Stating the case & 36 & 32.7 & 34 & 30.9 & 40 & 36.4 \\
\hline & & Control report & 26 & 23.6 & 29 & 26.4 & 55 & 50 \\
\hline & e magnitude and significanc & of the $\varphi$-criterio & & & & & & $7 *$ \\
\hline 5 & Love & Stating the case & 16 & 14.5 & 64 & 58.2 & 30 & 27.3 \\
\hline & & Control report & 8 & 7.3 & 59 & 53.7 & 44 & 40 \\
\hline & e magnitude and significanc & of the $\varphi$-criterio & & & & & & $5 *$ \\
\hline & Learning new things in & Stating the case & 51 & 46.4 & 41 & 37.3 & 18 & 16.3 \\
\hline 6 & the world, nature, man & Control report & 30 & 27.3 & 44 & 40 & 36 & 32.7 \\
\hline & e magnitude and significanc & of the $\varphi$-criterio & 2.9 & $9 * *$ & & & & $* *$ \\
\hline 7 & High social status and & Stating the case & 23 & 20.9 & 65 & 59.1 & 22 & 20 \\
\hline & people management & Control report & 10 & 9.1 & 61 & 55.5 & 39 & 35.4 \\
\hline & e magnitude and significanc & of the $\varphi$-criterio & & & & & & \\
\hline & Recognition and respect & Stating the case & 19 & 17.3 & 49 & 44.5 & 42 & 38.2 \\
\hline 8 & of people & Control report & 5 & 4.5 & 55 & 50 & 50 & 45.5 \\
\hline & e magnitude and significanc & of the $\varphi$-criterio & 3.1 & $9 * *$ & & & & \\
\hline 9 & Social activity & Stating the case & 48 & 43.6 & 44 & 40 & 18 & 16.4 \\
\hline & & Control report & 28 & 25.5 & 40 & 36.4 & 42 & 38.1 \\
\hline & e magnitude and significanc & of the $\varphi$-criterio & & & & & & $1 * *$ \\
\hline 10 & Communication & Stating the case & 23 & 20.9 & 73 & 66.4 & 14 & 12.7 \\
\hline & & Control report & 13 & 11.8 & 70 & 63,6 & 27 & 24,6 \\
\hline & e magnitude and significanc & of the $\varphi$-criterio & & & & & & $7 * *$ \\
\hline 11 & Health & Stating the case & 31 & 28.1 & 50 & 45.5 & 29 & 26.4 \\
\hline & & Control report & 21 & 19.1 & 43 & 39.1 & 46 & 41.8 \\
\hline & e magnitude and significa & of the $\varphi$-criterio & & & & & 2.4 & $5 * *$ \\
\hline
\end{tabular}

Note: *1.64-p $\geq 0.05, * 2.31-\mathrm{p} \geq 0.01$

\section{Conclusions}

The analysis of intra-group differences using the Fisher's $\varphi$-criterion for the indicator " high level "of the scales" high material "well-being", "search and enjoyment of the beautiful", "learning new things in the world, nature, man", " social activity and health "revealed statistically significant differences at the p 0.01 level of significance, the scales" help and 
mercy to other people"," love " revealed statistically significant differences at the p 0.05 level of significance.

The determination of the statistical significance of the differences in the indicators of the formation of the motivational sphere of students in all the diagnostic methods used with the Fisher criterion confirmed the effectiveness of the experimental work on the development of the motivational sphere of personality in students-future psychologists and teacherspsychologists in the process of studying the disciplines of socio-psychological orientation by means of training for the development of professional motivation as a condition for the success of the professional formation of a psychologist and a teacher-psychologist.

Thus, the process of preparing bachelors of the psychological and pedagogical direction of training on professional activity field is multidimensional and time-consuming, since at the theoretical and practical level it is necessary to master the methods of communication, management, interaction, diagnosis, forecasting, methods and means of correction, rehabilitation and protection of the individual. These fundamental components of professional activity, probably, should determine the content side of the training of bachelors-future psychologists and teachers-psychologists by means of training the development of professional motivation as a condition for the success of their professional development.

\section{References}

1. M.G. Yanova, Structure of professional competence of teacher Pedagogical journal, 4, 63-73 (2012)

2. E.M. Borodulin, A.G. Portnov, E.S. Kagan, Acmeological competence of the individual in the professional activities of teachers, Psychological research, 5(25), 9 (2012)

3. Danijela S., Petrović, Tijana Jokić and Bruno Leutwyler, Motivational aspects of teachers' intercultural competence: Development and psychometric evaluation of new scales for the assessment of motivational orientation, 49(4), 393-413 (2016)

4. Madasu Bhaskara Rao, Motivation of teachers in higher education, Journal of Applied Research in Higher Education, 8(4), 469-488 (2016)

5. Sevtap Karaoglu, Motivating Language Learners to Succeed, Tesol international association, URL: http://www.tesol.org/read-andpublish/journals/other-serialpublications/compleat-links/compleat-linksvolume-5-issue-2-(june-2008)/motivatinglanguage-learners-to-succeed (2008)

6. Madasu Bhaskara Rao, Motivation of teachers in higher education, Journal of Applied Research in Higher Education, 8(4), 469-488 (2016).

7. M. Lyle, J.R. Competence at work Models for Superior Performance, 384 (2005)

8. R. Pekrun, Emotions and Learning, Educational Practices, 24, 6-29 (2014)

9. T. Garcia, P.R. Pintrich, Regulating motivation and cognition in the classroom: The role of self-schemas and selfregulatory strategies, Self-regulation of learning and performance: Issues and educational applications, 127-153 (1994)

10. A.J. Martin, M. Dowson, Interpersonal Relationships, Motivation, Engagement, and Achievement: Yields for Theory, Current Issues, and Educational Practice, 79 (1), 327-365 (2009) 
11. M.T. Wang, J.S. Eccles, Social Support Matters: Longitudinal Effects of Social Support on Three Dimensions of School Engagement From Middle to High School, Child development, 83 (3), 877-895 (2012)

12. S. Hidi, K.A. Renninger, The Four-Phase Model of Interest Development, Educational Psychologist, 41(2), 111-127 (2006)

13. E.L. Deci, R.M. Ryan, Intrinsic motivation and self-determination in human behavior, $45(1985)$

14. D.H. Schunk, S.D. Miller, Self-efficacy and adolescents' motivation, Academic motivation of adolescents, 29-52 (2002)

15. K.J. Pugh, C.M. Bergstrom, B. Spencer, Profiles of transformative engagement: Identification, description, and relation to learning and instruction, Science Education, 101(3), 369-398 (2017)

16. V.K. Vilunas, Psychological mechanisms of learning motivation, 288 (1990)

17. V.I. Kovalev, Motives of behavior and activity, 192 (1988)

18. A.N. Leontiev, Needs, motives and emotions, 40 (1971)

19. T.V. Emelyanova, A.A. Stepanko, Model of the process of formation of motivational competence of future teachers of inclusive education, Baltic Humanitarian Journal, 7, $1(22), 237-240$ (2018) 